\title{
Cancer: a family at risk
}

\author{
Katarzyna Woźniak ${ }^{1}$, Dariusz lżycki² \\ 1Studium Doktoranckie, Uniwersytet Medyczny im. Karola Marcinkowskiego w Poznaniu \\ ${ }^{2}$ Zakład Immunologii Nowotworów, Wydział Lekarski II, Uniwersytet Medyczny im. Karola Marcinkowskiego w Poznaniu
}

\begin{abstract}
The diagnosis of cancer is a family experience that changes the lives of all its members, bringing an immense amount of stress and many challenging situations. The daily routine, common activities and distribution of duties all have to change. Family members follow the phases of the disease, very often suffering comparable or greater distress than the patient. They use various coping methods which aim at helping both the sick relative and themselves. These methods, together with emotional responses, change over time according to the phase of the disease.

Cancer puts the family at risk since it imposes an alternation in the relations among family members. It affects the couple's relationship, their sex life, and it can also be a cause of major trauma among their children and adolescents. The diagnosis of cancer brings also individual risks for the family members in terms of psychological and physical health impairment.

Family caregivers often feel overloaded with the additional obligations and roles they have to pick up. They find it increasingly burdening to care full-time for the household and provide emotional support for the patient. The family's problems and the way family members regard the disease may be also a result of the family system they are in. family.

This article describes the nature of caregiving to a patient with cancer and the biggest concerns for the
\end{abstract}

Key words: oncology, cancer, family, family burden, family stress.

\section{Introduction}

Cancer is a family experience, and often family members have as many problems coping with it as does the diagnosed patient. The family goes through different stages of adjusting to the disease. The emotional reactions may include anger, resentment, guilt and adjustment pain, and may or may not lead to the acceptance of the disease [1]. The cancer's diagnosis, as well as the subsequent phases of the disease and its treatment, may be a source of intense stress both for the patient and for the family. Patients and their relatives need to face the challenge of a life defined with uncertainty; treatment routines, the threat of recurrence or the failure of the treatment. According to the treatment results, we may refer to 'orphaned families and their psychological problems' or the 'survivors who need to live with the ghost of cancer' both in terms of the possible return of the disease or its genetic burden. Christ [2] identified main transition points for the patient and the family, being: diagnosis, treatment initiation, treatment completion, cure, treatment recurrence, decision to discontinue treatment, terminal illness and death. All of these may be a source of intense stress and concern and may bring about the destabilisation of family life.

With advances in medical technology and modern treatment methods, there are an increasing number of cancer survivors, yet still many people die from the disease. The diagnosis, treatment process, remissions and recurrence may all be grounds for considerable stress requiring the need for psychological and social adjustments, both for the patient and the family [3]. Furthermore, increasingly cancer care is provided at home, making family members the ultimate caregivers in assisting patients with everyday tasks, substituting for them in their duties and performing medical procedures. It was assessed that in the active period of treatment, caregiving may last from 14 to 24 months. The levels of involvement vary accordingly to the severity of the symptoms, treatment and disease stage [4]. Throughout this article, 'caregiver' is used to denote a family caregiver rather than a professional one. Family caregivers might be close relatives like spouses or children, but also children-in-law or more distant relatives.

Cassileth [5] defined several areas, which affect family functioning. First of all, cancer may be a threat to the 
previous model of family interaction. It brings the alternation of roles, which can be perceived by one as a loss and by the others as an excessive overload. Secondly, the disease forces the alteration of future plans due to the fact that the presence of cancer introduces a sense of uncertainty. Some families need to refrain from planning for the future and this can destabilise family functioning, bringing a sense of lack of goals or suspension. Thirdly, it affects the functioning of family members in external groups like, for instance, job or school environments. Also new groups of functioning appear - doctors, nurses, and other patients and their families. All of these people create a new environment and are of tremendous importance for the patient and his/her family.

Cancer is a disease that can concerns anybody, of any age. Thus, families may experience different concerns and issues according to their developmental stage and age. Childless couples who are just establishing an atmosphere of mutuality will have different needs and problems than those couples who have been together for many years and have adolescent children, or others who are at the end of their life span [6]. These result in the creation of different target groups for psychological intervention, with different characteristics and ways of dealing with them. Sadly, within the medical establishments, not enough attention is given to the family's condition. No matter what the phase of the cancer, it always makes a tremendous impact on family functioning, destroying the everyday rhythm, and present and future plans.

\section{A family in the course of cancer}

The role of a family in the course of cancer changes according to the needs of the patient and the cancer's phase [1]. In the diagnosis phase, depending on the type of family, a big mobilisation, with readiness to give support to the patient, is observed. Family members try to get information about the diagnosis, treatment and chances of survival. Other family types may avoid talking about the cancer to avoid creating an additional stress for the patient. Also, very often both the patient and family members try to search for the reasons for the sickness. Looking to find some sense in the universe is a very common tendency, which results from the conviction that everything in the world has its place and reason [7]. Depending on the family's coping style, if it is a task concentrated family, attitude towards the sickness may promote healthy behaviour or strengthen the will of the patient to fight.

The treatment phase is associated with the alternation of roles within the family. Very often all of the members need to cope with the treatment symptoms, they need to substitute for the sick person with his/her household obligations, and take him/her to the hospital for chemotherapy or radiotherapy. This can be very burdening, both physically and psychologically. In par- ticular, the family may feel in suspension between fear and hope for the treatment result.

The chronic phase of the disease may last for months or even years including periods of treatment and remission. It is also the time when the family slowly returns to its routine life. In some families the end of chemotherapy or radiotherapy is recognised as the end of the disease itself. They may thereby impose a pressure on the patient to pick up his/her old responsibilities, behave healthily, and stop pondering on the disease, which should remain in the past. This pressure to 'come back to life as it was before' can create an uncomfortable situation for the patient who may not yet feel strong enough to resume full activity or who needs his/her family to still support him/her. Other families, fearing or not yet knowing whether the patient is or is not healthy, may fall into overprotection, thereby hindering the patient's social rehabilitation or putting him/ her in a position in which he/she feels unneeded or isolated from family life.

The recovery phase is also fraught with psychological problems. First of all, there is always the threat that the cancer can come back. The family have to constantly face the fear that there could be a recurrence, and every check-up brings a tension that the tests could detect new carcinogenic cells. Secondly, some treatment processes bring long-term effects on the health of the patient, i.e. organ dysfunctions or persistent conditioned reflexes, which can be a source of stress or negative psychological conditions both in the patient and his/her family. Thirdly, having a close relative with cancer always puts a burden on the offspring in terms of genetics. In these ways cancer always stays in the family, forcing it to live in its shadow.

The end of the life phase is the most stressful for the family members [7]. The strong stress reaction may be caused both by the fear of separation and of staying alone, as well as by the anticipated pain the patient will have to face, the lack of control over the situation, and the moment of death. The way family members are able to deal with the dying of their relatives depends on their own psychological and physical condition and also on their support network.

\section{Family needs}

While taking care of a sick patient, most caregivers share some common needs which unfortunately are not always possible to be fulfilled. All of them have a need for information, for feeling close to and needed by the patient, and to have a chance to get external support whereby they can speak about their own problems - to 'ventilate' their emotions [7]. According to Friöriksdóttir et al. [8], the top 3 important needs for the family members are associated with being assured that the best possible care is given to the patient, that 
the professionals care about the patient and that they have their questions answered honestly. Up to $30 \%$ of those needs are unmet by the medical professionals. In reference to needs rated as less important those numbers were reaching up to almost $50 \%$. Stenberg et al. [9] have indicated over 200 types of problems and unmet needs reported by the caregivers, with the information need being indicated as the most important.

\section{Negative emotional and cognitive reactions of a family towards cancer}

Family members go through emotional stages accordingly to the sickness phase. Anger is the first intense reaction which is usually directed towards the medical staff. It can be shown as a reaction to the diagnosis or if the family considers that the care provided by the doctors or nurses is unprofessional or not sufficiently caring [2]. Although directed towards the external environment, their anger can have its roots in a sense of guilt, injustice or a lack of comprehension. Family members may accuse themselves of not being attentive enough and for not forcing the patient to have regular medical examinations and a healthier lifestyle. In some cases they might perceive the disease as a punishment for their or the patient's sins. They can experience an undefined resentment to God, fate, or towards their family or other people for their behaviour, decisions and attitudes towards the patient. Research by Manne et al. [10] showed that negative attitudes toward the patient's disease among family members may be associated with an increased necessity of caregiving to the patient, which in turn interferes with the plans, out-of-home activities of the caregiver. Reluctance arising from such a situation may explain the distancing from the patient and adopting critical attitude towards him/her. A rewarding relationship between spouses has been shown a protective factor against the cynical attitude towards the patient. Among couples investigated by Manne, those who rated their relationship as good before the beginning of the disease, the limitation of the time caregivers had for their own activities did not result in distress and, in return, did not cause a critical attitude towards the patient withdrawing.

\section{A family in the caregiving role}

Caregiving is a multifaceted role ranging from simple activities, like providing transport to medical care establishments, to physical care and the performance of some medical activities. It also includes providing the patient with emotional support by sharing their feelings of mortality, uncertainty, fear and hope [11]. Cancer brings an alternation of family roles and a shift in housekeeping obligations as the duty of sustaining the house falls on one partner. The substitution of roles is much easier in families characterised by a flexible division of responsibilities. Rigid families can experience frustration and a sense of emptiness, with the family members feeling overburdened by the new duties [2].

Research by Ferrario et al. [3] shows that $20 \%$ of caregivers have practical or economic problems with fulfilling extra obligations resulting from caregiving, for example, taking the patient to the hospital for check-ups. The same research also demonstrated that $60 \%$ of caregivers had to give up their hobbies and meeting friends. Increased family responsibilities may influence disruption in coping strategies as social interactions which have stress reduction roles are limited [11]. The alternation within a family structure does not necessarily have to take place on the partner-partner level. The child of a sick parent can take his/her role, thereby being a wife or husband to the healthy spouse, the main source of support for the cancer patient, and a parent for other siblings.

In general, two separate processes might be observed within the family. On the one hand, the lives of all the family centre over the patient. On the other hand, Thorne [12] reported that family members have an enormous need to live as normally as possible, to have faith in medical professionals and to maintain a positive attitude. Wanting to keep things 'as they were before' can have both positive and negative effects. It can be a buffer against negative thinking, preventing the exclusion of the patient from family life. Alternatively, keeping up appearances can lead to a denial of the sickness and negative psychological symptoms, like anger caused when the treatment does not go as planned or a lack of agreement within the family concerning the forthcoming death. Some family members might expect that just after treatment the patient would pick up the roles he/she neglected during treatment. This puts the patient in an uncomfortable situation between his/her family's demands for 'being healthy' and his/ her own physical state.

\section{Cancer as a family risk}

In the event of cancer the whole family system is at risk and so are individual family members. Cancer exerts a change in family's system balance, redefinition of the rules. The individual costs are associated with experiencing the overload of stress, negative emotions, role strain and may lead to physical and psychological health impairment.

\section{System risks}

A family lives in a system and this system is dynamic, it is a net of mutual relations. The coping abilities of a family are unique and are the result of communication patterns, value systems, and the division of responsi- 
bilities [13]. The reaction of a family to the sickness of one of its members is the result of this family system.

Generally, there are two types of system characteristics. The first is characterised by a lack of individual differentiation among the family members and by their inter-dependency. These families give the impression of being very close but in reality, within the family environment, rules prevent open communication and there is a big emphasis on 'conditional love'. They show disapproval towards any actions that would try to break their system. These types of families tend to close themselves off in a situation of crisis and any help from outside the system is regarded as unneeded, as threatening. The second type of a system is characterised by weak internal relations and separatism. Family members tend to achieve their own goals independently of the others. In a situation of crisis there is no exchange of information and communication [2]. Most family systems are in the middle of these two poles, with an optimum system being the one in which the negative features of the two (mentioned above) are overcome. These families can be characterised as elastic, with open communication and tolerance. In this system, coping with the crisis which is cancer is the most efficient.

The appearance of the disease may influence the functioning of the family system in different ways. In order to assess the coping abilities of a family confronting cancer, several factors should be taken into consideration, including: the family's knowledge of the disease, its perceived threat, the evaluation of family resources, and the family's past experience in dealing with similar crisis situations [2, 14]. When one family member suffers from cancer, the family system in confronted with a new situation. This demands adaptive changes in all aspects of family functioning. Adaptive process is dependent on the stage of the illness and its course [15]. When one family member gets chronically ill the most characteristic tendency within the family system in the need for cohesion, being close with each other [10]. The family members focus on the patient, try to provide him/her with their support. Sometimes, however, the new situation evokes maladaptive attitudes in family members, expressed by hostility, blaming the patient for the resulting situation, defeatism, gloom, lack of faith in the efficacy of the treatment. In general, the way families cope with the situation of cancer is dependent on the family - the stiffer the family structure is, the more problems are experienced by family members in adapting to the new situation. It also happens that, as a result of the difficulties and the crisis, the family breaks up [1].

\section{Groups of risks}

Cancer brings new challenges to all family members; it also constitutes a threat both in terms of the quality of relationships and also psychological effects. The process of adjusting to the disease leads to an alternation in relations and behaviour between spouses, children and parents.

For sure, cancer has a considerable impact on marital relationships [3]. After diagnosis some marriages may have problems in communication, especially among those couples where the communication was very good before, because they are those who find it the most difficult to accept the new situation [2]. Some partners decide to protect the other by not sharing the full information about his/her condition. Exclusion may be a reason for vast communication problems, causing the partners to drift apart. Other causes for communication distortion are the differences between partner's communication needs, coping strategies and their ability to express emotions. Sometimes it happens that one of the partners has a big requirement for information, whereas the other would prefer to cut him/herself off from any news concerning the cancer.

Another problem occurring between the couple is the quality of their sex life, which is often very low since partners may refuse to have any. Very often as a result of therapy patients lose their hair or weight. Sometimes the treatment requires surgery and removal of breast(s), testicle(s), or the making of a stoma. A lot of women after mastectomy suffer from the feeling of reduced sense of femininity, which can limit their willingness to restart sexual activity [16]. Other unfavourable effects may include: dyspareunia in women, problems with erection and ejaculation in men, or a general decrease of libido [7]. Due to these body changes patients themselves may feel unattractive or repulsive, or other family members may view them that way. A lack of sex life can also be caused by the alternation in the relations between the couple. The healthy spouse takes the role of the caregiver, which can decrease the sexual needs of both partners [2]. The conviction by the healthy spouse that at the time of treatment the patient is not interested in any sexual contact, results in them not even raising the subject. For the sick partner this situation is very painful, he/she perceives the behaviour of the partner as confirmation of his/her unattractiveness, making the burden of cancer even more unbearable.

It is highly stressful for everyone who is experiencing cancer within their family, however the perception of the disease depends upon the person who is sick. Research has shown that having a child sick with cancer may cause emotional instability, uncertainty and strain among the family members. The parents of children with cancer are describing it as the most overwhelming experience of their lives [17], influencing their daily routines and being vastly energy consuming and burdening. It seems that mothers and fathers of sick children not only have different patterns of reacting emotionally 
to the disease but also they have varied coping methods. The study of 164 Taiwanese families [18] showed the mothers to be less satisfied with their marriage and experiencing more depressive symptoms, anxiety and somatisation in comparison to the fathers. Parents of children with cancer meet a lot of challenges that change over time. They need to face not only the emotional reaction of their child to the sickness and treatment process, but also to handle their own emotions. According to research by Svavarsdottir [17], among the most burdening and time-consuming activities that parents were mentioning was managing the behavioural problems of both their sick child and other offspring, planning and coordinating family activities, and giving emotional support to the spouse or partner. If there are other children in the family, the parents need to take care of their wellbeing too, and although a sick child is in an unusual situation, it still has a need to be raised and educated. Parents therefore have to learn how to negotiate between handling the sickness and parental tasks.

It is clear that having a parent with cancer can lead to stress symptoms in their children. Both small children and adolescents have problems in defining their exact emotions when they learn about the diagnosis of their parents. Similarly to adults they might feel anger, grief and feelings of rejection. Some of them can have the idea that the sickness of their parents is some sort of punishment or that they are responsible for the parent. Other symptoms may include: excessive crying over small stressors, a lack of appetite, vomiting, stomach pains, sleep disorders, frequent nightmares, an intensification of asthma, skin rashes, headaches, refusing to go to school or getting poorer marks, and aggressive or destructive behaviour.

Among the groups most at risk are adolescents, especially daughters. Research into the coping of the adolescent group whose mothers have breast cancer is often inconsistent, showing a big variation, ranging from exhibiting psychological disturbances through to coping well with the situation. It seems that among adolescents the reaction to the disease varies according to family functioning and communication, parental coping and the adolescent's own characteristics [19]. Poor family functioning and cohesiveness reflect in an adolescent's emotional and behavioural problems and increases the stress level. Also, some evidence shows that a mother's depression has considerable effects on her children's psychological condition. In the most extreme cases, children of cancer suffering parents may develop long-standing post-traumatic stress disorder.

\section{Cancer as a cause of an individual risk}

When a family member is ill, his/her family is exposed to various types of stressors. All new situations, roles and experienced emotions can be considered as risk factors for the development of various kinds of disorders. International research shows that caregiving for cancer patients is associated with a significant decline in mental health status and overall QOL [20]. Disorders most commonly mentioned in international literature are sense of burden, distress, anxiety and depression [4] all of which are interdependent. Increasing emphasis in the research on caregiving's effects is put on caregivers' health, also in the context of immunocompetence $[4,20]$.

\section{Burden}

'Burden' may be defined as a multidimensional concept with objective and subjective components. 'Objective burden' is defined as specific happenings and activities related to caregiving, for instance, financial problems or personal activity limitations. 'Subjective burden', on the other hand, encompasses affective responses to the caregiver experience, such as feelings and emotions related to fear, strain and guilt [7, 22, 23]. Ryn's [24] study of more than 600 informal caregivers of people suffering from colon and lung cancers demonstrated that more than half of them took care of the sick without the help of other family members, which accounted for a large source of their load. Other types of burden experienced by respondents were: financial problems, combining caring with work, caring for other family members, their own health problems, lack of education in the field of medical procedures they were performing. The burden of care extends from diagnosis, treatment and, in many cases, to death. The feeling of overload might be dependent on the type of activities performed for the patient and on the level of sense of being limited by them experienced by the caregiver. For example, bathing the patient is perceived to be more burdensome than doing shopping for him/her [25]. Furthermore, it has been found that the emotional strain is more burdensome than the actual activities related to providing care or causing a destabilisation in family daily life. The potential factors influencing feelings of burden and distress may include: rapid fluctuations in the medical status of a patient, the effects of the treatment, frequent invasive medical procedures and (as a consequence) an alteration in physical appearance, the possibility of death [26], level of support that caregivers receive, the caregiver's sex [27], caregivers' income, age [28] and education level [29].

\section{Distress}

Family members of patients with cancer may experience distress as an effect of their caregiving, with negative symptoms which may include: anxiety, depression, 
a sense of burden, helplessness, and fear [30]. Many researches rate that the level of distress experienced by family members is comparable [31-33], or even higher, than the one experienced by the patient $[34,35]$. For the male partners of breast cancer patients, factors such as couple adaptation to the illness, disruption of communication [36], higher levels of distress in the patient [32], mastectomy [37] and lack of social support [38] may indicate that couples or men are at risk for developing chronic stress and adjustment disorders.

The level of distress may be reinforced by the caregiver's reluctance to pick up the new role because they are unfamiliar with the tasks they must provide, they feel unable or are not professionally prepared to carry out direct care or perform complex medical procedures, or they find it problematic to cope with the disease of the patient while simultaneously sustaining family routines, providing emotional support to other family members and fulfilling housekeeping duties [15, 22, 31, 39]. Caregivers find it difficult to negotiate the additional requirements of the family member's sickness with their own professional life. This adds to their overall level of psychological distress which in turn may cause problems in their work place, including withdrawal or absence, a reduction in productivity, and as a result, a threat of dismissal and/or financial problems [11, 40]. The caregiver may experience higher levels of distress correlating to the patients' worsening functional and medical condition as greater assistance with daily living activities must be provided. As the disease develops, its symptoms may become more intense and so require an increase in assistance with symptom management from the family. These may all be vastly burdening for the caregivers, causing them to experience distress.

The level of distress is also connected to the phase of the illness the patient is in. Being a family carer to a patient nearing the end of his/her life can be a challenging and traumatic experience, including complex physical and medical care, financial administration, difficult decision making, giving support, and planning and coordinating all-embracing care. Moreover, family palliative carers also need to face the grief and loss associated with their relative's death [4]. Not a lot of research focuses on the effects on the carers themselves when providing care for patients with terminal cancer. However, the available data report [22] that regardless of the amount of care provided, the emotional distress the caregivers were experiencing was impairing their ability to participate in daily activity. This reaction is probably caused by the perception of the end of life event, caregivers realise that death is imminent which causes them to experience distress independently of the actual care effort they are making. The majority of research shows that $20 \%$ to $30 \%$ of spouses anticipating the possible loss of their partner's life suffer from psychological distress and increased morbidity [40]. It is also reported that at the time of the diagnosis spouses may experience the same distress levels as the patients, and further, in some cases this distress may remain unresolved for one or more years [11, 39]. The psychological support seems to play a significant role in supressing patients' in terminal stage anxiety and depression [42]. Prolonged stress may reduce the capacity of spouses to provide adequate care towards patients and, of course, has a destructive influence on the physical and social functioning of the person. The effects of an extended period of stress may include anxiety, insomnia, a sense of isolation, problems with concentration, burnout, despondency, mood instability and eating disorders.

\section{Depression}

Anxiety and depression are common in family caregivers and, what is often underlined, they are correlated [40, 43-45]. According to Park et al. [45], approximately $40 \%$ of family caregivers suffer from anxiety and more than $80 \%$ experience depressive symptoms. However in non-Asiatic countries this percentage is lower. Depression is a frequent consequence of caregiving for a cancer patient. It may be equal to or exceeding the depressive symptoms experienced by the patient [27] and is directly connected to the level of the quality of life [8]. Its intensity depends on many patient- and caregiverassociated factors [35, 43]. Most commonly mentioned risk factors are education level, socioeconomic status [45-47], family environment, which includes the family cohesion, expressiveness, perceived burden [47], blaming the patient for the cancer [48], being a spouse caregiver [25]. It is also widely reported that women are more susceptible to developing depression than men $[40,49]$. There is, however, a big piece of evidence that male partners of females with breast cancer also develop depressive symptoms. Factors that increase the probability of developing depression in partners of women with breast cancer are dissatisfaction with the marital relationship, avoiding attachment style [50], dissatisfaction with sexual life [20]. In a study of Lewis et al. [51] on risk factors for depression in partners of breast cancer women, it was found that men who are older, less educated, in shorter lasting marriages, more concerned about the health of the wife and their situation at work, uncertain about the future and the marriage, who were showing lower levels of adaptation, were more likely to develop depressive disorders.

The treatment phase is also associated with appearance of depressive symptoms. For instance, during chemotherapy, incidences of depression are rare for both sexes. There are no significant differences between men and women in the level of depressive symptoms. Studies suggest regular visits at the hospital and contact with medical staff give the caregivers the necessary support [46]. 
The high level of anxiety among caregivers may be related to concerns about the future, loss of a loved one, fear of loneliness, child care, taking over household duties [50], caring for a sick person at home, experiencing physical pain, younger age and lower self-efficacy [44].

Research by Glasdam et al. [52] shows that $18 \%$ of spouses of cancer patients suffer from anxiety, while in research done by Gaston-Johansson et al. [11] this level was defined as moderate. The level of anxiety is dependent on variables such as gender, age, family development cycle [43]. Among women, breast cancer anxiety is one of the major psychological problems, estimated to occur in $10-50 \%$ of patients [35]. This information is important because as in the case of other disorders, including anxiety levels coupled reactions is determined by the patient or the partner reaction. Research by Segrin et al. [35] showed that the level of anxiety in women with breast cancer and their partners were interdependent, but in the direction partner - patient. This means that partners were showing higher levels of anxiety as a response to higher levels of anxiety in their sick partners. Anxiety among partners was positively associated with depression, distress, sense of mental and physical fatigue, and negative coping with illness by the patients.

\section{Health problems}

Costs of caregiving cannot be perceived only in the psychological dimension, as caregivers may also experience heart disease, hypertension and impaired immune function, putting them at a higher risk of various infections and cancer [53]. Prolonged chronic stress, sense of burden, depression and anxiety can be associated with health impairment [53-55]. Caregivers may experience altered appetite, headaches, fatigue, pain, insomnia, high blood pressure [28]. Chronic stress has an aggravating impact on the immune system [56] in terms of its impact on natural and specific immune response. Chronic character of the stressors may be associated with their duration but also with changes in identity and social role [57]. Research on partners of women with breast cancer [21] has reported that the long duration of stress experienced by the spouses was characterised by a less effective cellular immune function. Suppression of DTH response was greater in men whose wives were sick for longer, experienced greater psychological distress and had more severe depressive symptoms.

\section{Individual characteristics and the cost of cancer in the family}

The risk which cancer can impose on family members can be mediated by individual characteristics like the coping style or personality traits. Coping refers to "constantly changing cognitive and behavioural efforts to manage certain external and internal demands assessed by a person as burdensome or excessing the resources" [58]. It was proved that problem-focused strategies are far more efficient in dealing with difficult situations than emotion-oriented strategies [59]. Active ways of coping are also associated with social support in contrast with depressive coping [15]. The coping strategy seems to have a crucial role in dealing with the strain of cancer among family caregivers. According to Gaugler et al. [60], negative strategies, and negative judgment of own coping strategies, were associated with the experience of role entrapment, feeling of fatigue, distress with symptoms of depression and anxiety. Family members who were using more positive coping strategies were experiencing less emotional exhaustion. This is consistent with the research of Papastavrou et al. [27] stating that highly burdened relatives used emotion-focused strategies.

Some authors underline that the caregiver's stress may be associated with the personality traits or temper which can result from the occurrence of depression among family members. A high level of neuroticism influences the perception of distressing situations and also impacts upon the coping strategies $[3,11]$. Some research indicates that burden may be highly predictive of depression; others report no connection [11]. Depression might be fostered by age and the level of education, the older and the less educated the people, the higher is the possibility of the occurrence of this disorder [3].

Sex and the nature of relationship type are also related to perception of caregiving as stressful or beneficial. It seems that for women and, especially adult, daughters of cancer patients the experience is more likely to be perceived as burdensome, whereas for husbands it is more favourable [11].

\section{Conclusions}

Cancer is a difficult experience for a family as a system as well as for all its members. The diagnosis affects the stability of the family system, forcing sudden and unwanted changes upon it. Cancer not only affects current relations within the family, it can also have farreaching consequences. Facing the diagnosis and then dealing with treatment, constant indisposition and the threat of death, can strain the family's coping abilities and put it into considerable distress. The individual costs experienced by family members may include sense of burden, depression and anxiety, stress. Those costs cannot be considered as psychological impairment only, but also as a threat to the physical health of the family caregivers. 


\section{Disclosure}

Authors report no conflicts of interest.

\section{References}

1. Budziszewska BK, Piusinska-Macoch R, Sulek K, et al. Psychologiczne problemy rodziny pacjentów z chorobami nowotworowymi krwi w koncepcji systemowej. Acta Haematol Pol 2005; 36: 317-325.

2. Christ GH. A psychosocial assessment framework for cancer patients and their families. Health Soc Work 1983; 8: 57-64.

3. Ferrario SR, Zotti AM, Massara G, et al. A comparative assessment of psychological ad psychosocial characteristics of cancer patients and their caregivers. Psychooncology 2003; 12: 1-7.

4. Given B, Given C, Sherwood P. The challenge of quality cancer care for family caregivers. Semin Oncol Nurs 2012; 28: 205-212.

5. Cassileth BR. Psychological preparation of the patient and family. Cancer 1987; 60: 547-552.

6. Cohen MM, Wellisch DK. Living in limbo: psychosocial intervention in families with cancer patient. Am J Psychother 1987; 32: 561-571.

7. de Walden-Galuszko K. Psychoonkologia w praktyce klinicznej. Wydawnictwo Lekarskie PZWL, Warszawa 2011.

8. Friöriksdóttir N, Saevarsdótti T, Halfdánardóttir SI, et al. Family members of cancer patients: needs, quality of life and symptoms of anxiety and depression. Acta Oncol 2011; 50: 252-258.

9. Stenberg U, Ruland CM, Miaskowski C. Review of the literature on the effects of caring for a patient with cancer. Psychooncology 2010; 19: 1013-1025.

10. Manne SL, Alfieri T, Taylor KL. Spousal negative responses to cancer patients: the role of social restriction, spouse mood, and relationship satisfaction. J Consult Clin Psychol 1999; 67: 352-361.

11. Gaston-Johansson F, Lachica EM, Fall-Dickson JM, et al. Psychological distress, fatigue, burden of care, and quality of life in primary caregivers of patients with breast cancer undergoing autologous bone marrow transplantation. Oncol Nurs Forum 2004; 31: 1161-1169.

12. Thorne S. The family cancer experience. Cancer Nurs 1985; 8: 285-291.

13. de Barbaro B (ed.). Wprowadzenie do systemowego rozumienia rodziny. Wydawnictwo Uniwersytetu Jagiellońskiego, Kraków 1999.

14. Matsubara TC, Carvalho EC, Canini SR, et al. Family crisis in the context of bone marrow transplantation: an integrative review. Rev Latino-Am Enfermagem 2007; 15: 665-670.

15. Kotkamp-Mothes N, Slawinsky D, Hindermann S, et al. Coping and psychological well being in families of elderly cancer patients. Crit Rev Oncol Hemat 2005; 55: 213-229.

16. Mącik D, Ziółkowska P, Kowalska M. Self-perception of women after mastectomy as an ego defence mechanism. Comparison with a group of healthy women. Contemp Oncol 2012; 16: 184-190.

17. Svavarsdottir EK. Caring for a child with cancer: a longitudinal perspective. J Adv Nurs 2004; 50: 153-161.

18. Yeh $\mathrm{CH}$. Gender differences of parental distress in children with cancer. J Adv Nurs 2002; 38: 598-606.

19. Edwards L, Watson M, St. James-Roberts I, et al. Adolescent's stress responses and psychological functioning when a parent has early breast cancer. Psychooncology 2008; 17: 1039-1047.

20. Milbury K, Badr H. Sexual problems, communication patterns, and depressive symptoms in couples coping with metastatic breast cancer. Psychooncology 2013; 22: 814-822.

21. Mortimer JS, Sephton SE, Kimerling R, et al. Chronic stress, depression and immunity in spouses of metastatic breast cancer patients. Clinical Psychologist 2005; 9: 59-63.

22. Given B, Wyatt G, Given C, et al. Burden and depression among caregivers of patients with cancer at the end of life. Oncol Nurs Forum 2004; 31: 1105-1117.

23. Bastawrous M. Caregiver burden - a critical discussion. Int J Nurs Stud 2013; 50: 431-441.

24. Ryn van M, Sanders S, Kahn K, et al. Objective burden, resources, and other stressors among informal cancer caregivers: a hidden quality issue? Psychooncology 2011; 20: 22-52.

25. Nijboer Ch, Tempelaar R, Sanderman R, et al. Cancer and caregiving: the impact on the caregiver's health. Psychooncology 1998; 7: 3-13.
26. Bull MJ. Factors influencing family caregiver burden and health. West J Nurs Res 1990; 12: 758-770.

27. Papastavrou E, Charalambous A, Tsangari H. Exploring the other side of cancer care: the informal caregiver. Eur J Oncol Nurs 2009; 13: 128-136.

28. Chang H, Chiou C, Chen N. Impact of mental health and caregiver burden on family caregivers' physical health. Arch Gerontol Geroat 2010; 50: 267-271.

29. Kim Y, Baker F, Spillers RL. Cancer caregivers' quality of life: effects of gender, relationship, and appraisal. J Pain Symptom Manage 2007; 34 294-304.

30. Hudson PL, Remedios C, Thomas K. A systematic review of psychosocial interventions for family carers of palliative care patients. BMC Palliat Care 2010; 9: 17

31. Kothamp-Mothes N, Slawinsky D, Hindermann S, et al. Coping and psychological well being in families of elderly cancer patients. Crit Rev Oncol Hematol 2005; 55: 213-229.

32. Gilbar O, Zusman A. The correlation between coping strategies, doctorpatient/spouse relationships and psychological distress among women cancer patients and their spouses. Psychooncology 2007; 16: 10101018.

33. Ben-Zur H, Gilbar O, Lev S. Coping with breast cancer: patient, spouse and dyad models. Psychosom Med 2001; 63: 32-39.

34. Edwards B, Clarke V. The psychological impact of cancer diagnosis on families: the influence of family functioning and patient's illness characteristics on depression and anxiety. Psychooncology 2004; 13: 562-576.

35. Segrin C, Badger T, Dorros SM, et al. Interdependent anxiety and psychological distress in women with breast cancer and their partners. Psychooncology 2007; 16: 634-643.

36. Foy S, Rose K. Men's experiences of their partner's primary and recurrent breast cancer. Eur J Oncol Nurs 2001; 5: 42-48.

37. Segrin C, Badger T, Sieger A, et al. Interpersonal well-being and mental health among male partners of women with breast cancer. Issues Ment Health Nurs 2006; 27: 371-389.

38. Hasson-Ohayon I, Goldzweig G, Braun M, et al. Women with advanced breast cancer and their spouses: diversity of support and psychological distress. Psychooncology 2010; 19: 1195-1204.

39. Foxall MJ, Gaston-Johansson F. Burden and health outcomes of family caregivers of hospitalized bone marrow transplant patients. J Adv Nurs 1996; 24: 915-923.

40. Goren A, Gilloteau I, Lees M, et al. Quantifying the burden of informal caregiving for patients with cancer in Europe. Support Care Cancer 2014; 22: 1637-1646.

41. Blanchard CG, Albrecht TL, Ruckdeschel JC. The crisis of cancer: psychological impact on family caregivers. Oncology 1997; 11: 189-202.

42. Glińska J, Adamska E, Lewandowska M, et al. Evaluation of the psychological state of patients with advanced cancer and the impact of support on their emotional condition. Contemp Oncol 2012; 16: 563-568.

43. Edwards B, Clarke V. The psychological impact of cancer diagnosis on families: the influence of family functioning and patient's illness characteristics on depression and anxiety. Psychooncology 2004; 13: 562-576.

44. Lee $\mathrm{Y}$, Liao $\mathrm{Y}$, Liao $\mathrm{W}$, et al. Anxiety, depression and related factors in family caregivers of newly diagnosed lung cancer patients before first treatment. Psychooncology 2013; 22: 2617-2623.

45. Park B, Kim SY, Shin J, et al. Prevalence and predictors of anxiety and depression among family caregivers of cancer patients: a nationwide survey of patient - family caregiver dyads in Korea. Support Care Cancer 2013; 21: 2799-2807.

46. Williams A, Holmes-Tisch AJ, Dixon J, et al. Factors associated with depressive symptoms in cancer family caregivers of patients receiving chemotherapy. Support Care Cancer 2013; 21: 2387-2394.

47. Rhee YS, Yun YH, Park S, et al. Depression in family caregivers of cancer patients: the feeling of burden as a predictor of depression. J Clin Oncol 2008; 26: 5890-5895.

48. Siminoff LA, Wilson-Genderson M, Baker S. Depressive symptoms in lung cancer patients and their family caregivers and the influence of family environment. Psychooncology 2010; 19: 1285-1293.

49. Kim Y, Baker F, Spillers RL, et al. Psychological adjustment of cancer caregivers with multiple roles. Psychooncology 2006; 15: 795-804.

50. Duci V, Tahsini I. Perceived social support and coping styles as moderators for levels of anxiety, depression and quality of life in cancer caregivers: a literature review. Eur Sci J 2012; 8: 160-175. 
51. Lewis FM, Fletcher KA, Cochrane BB, et al. Predictors of depressed mood in spouses of women with breast cancer. J Clin Oncol 2008; 8: 1289-1295.

52. Glasdam S, Jensen AB, Madsen EL, et al. Anxiety and depression in cancer patients' spouses. Psychooncology 1996; 5: 23-29.

53. Kiecolt-Glaser JK, Preacher KJ, MacCallum RC, et al. Chronic stress and age-related increases in the proinflammatory cytokine IL-6. Proc Nat Acad Sci 2003; 100: 9090-9095.

54. Atanackovic D, Kroger H, Serke S, et al. Immune parameters in patients with anxiety or depression. J Affect Disorders 2004; 81: 201-209.

55. Kiecolt-Glaser JK, McGuire L, Robles TF, et al. Emotions, morbidity, and mortality: new perspectives from psychoneuroimmunology. Annu Rev Psychol 2002; 53: 83-107.
56. Gouin JP, Glaser R, Malarkey WB, et al. Chronic stress, daily stressors, and circulating inflammatory markers. Health Psychol 2012; 31: 264-268.

57. Segerstrom SC, Miller GE. Psychological stress and the human immune system: a meta-analytic study of 30 years of inquiry. Psychol Bull 2004; 130: 601-630.

58. Heszen I. Psychologia stresu. Wydawnictwo Naukowe PWN, Warszawa 2013.

59. Zeidner M, Ben-Zur H. Individual differences in anxiety, coping and posttraumatic stress in the aftermath of the Persian Gulf War. Pers Indiv Differ 1994; 16: 459-476.

60. Gaugler JE, Eppinger A, King J, et al. Coping and its effects on cancer. Support Care Cancer 2013; 21: 385-395. 